\title{
THE INFLUENCE OF NaCI SOLUTION FLOW RATE ON ION ABSORPTION OF CAPACITIVE ELECTRIC CARBON PLATE
}

\author{
Ellys Kumala Pramartaningthyas ${ }^{1}$ \\ ${ }^{1}$ Faculty of Engineering, Qomaruddin University \\ Gresik, 61152, Indonesia \\ ellys.kumala@gmail.com \\ DOI: $10.21107 /$ jps.v8i1.8596
}

\begin{abstract}
Research on desalination technology in seawater is being developed. This is because seawater has not been used optimally to meet community needs. On the other hand, the world community is currently faced with the problem of scarcity of clean water. The factors that influence these problems are the existence of deforestation, expansion of industrial and residential areas, pollution, and prolonged drought. One of the rapidly developing desalination systems is desalination technology using a capacitive carbon plate. The development of this desalination system technology is carried out using electrode plates made of carbon. These plates are capable of absorbing salt ions through the porous surface. The amount of ion absorbed is determined by the pore surface structure of the plate, the flow rate of salt, the number of plates used, the applied stress, and other factors. The rate of salt flow between the carbon plates determines the speed at which the salt ions reach the smallest pores on each plate surface. For this reason, in this article research has been carried out by testing the variation in the flow rate of $\mathrm{NaCl}$ solution to the number of salt ions absorbed on the carbon plate.
\end{abstract}

Keywords: absorption, carbon plate, flow rate, seawater.

\footnotetext{
${ }^{1}$ Corresponding Author
} 


\section{Introduction}

The scarcity of clean water is a crucial problem facing the world community today. One of them is when there is a prolonged drought, there are still many areas that need water. On the other hand, the expansion of industrial estates and residential areas causes forestry areas to become increasingly limited. This causes water infiltration into the soil which is very important in providing groundwater to be smaller(Ahmed \& Tewari, 2018). Water pollution carried out by the industrial sector and the people who throw garbage carelessly makes clean water supplies increasingly scarce. In addition, in agriculture, the use of pesticides can contaminate groundwater that is consumed by the community. This makes the level of clean water supply in the world decrease from year to year (Ahmed \& Tewari, 2018). One of the water resources that has not been widely used is seawater. Seawater occupies $70 \%$ of the earth's area and is currently not optimally utilized by the community. Apart from the technology to convert seawater into freshwater is a technology that is quite expensive, it is also a technology that requires quite high energy (Wu et al., 2016). For this reason, it is very important to develop a desalination technology that is inexpensive, energy-efficient, and environmentally friendly. So that it can be used well by people from various circles. So that is expected this seawater desalination technology can replenish clean water supplies for the community (Oren, 2008).

Capacitive deionization is an alternative technology for converting seawater into freshwater. This technology is efficient because it only requires a small amount of energy for the electrostatic force to bind the ions of the salt compound(Guo et al., 2020). In this desalination system, it is fabricated in the presence of two carbon electrode plates made from activated carbon powder which is synthesized using carbon molecules as a binder (Oren, 2008). Then the plates are connected to a DC electric current which has a low voltage. When the brine passes through the two electrodes, the $\mathrm{Na}+$ and $\mathrm{Cl}-$ ions will separate themselves into the electrode poles that attract them(Fritz et al., 2019). This capacitive desalination system works at a relatively small voltage so that this system is an energy-efficient and environmentallyfriendly system (Demirer et al., 2013).

The capacitive desalination system carbon plate is an electrode made from a mixing process between a PVA polymer and a binder(El-Deen et al., 2014). PVA polymer was chosen in the manufacture of this carbon plate because PVA is a polymer that dissolves easily in water. This results in a carbon plate that has a high absorption of salt ions (Ahmed \& Tewari, 2018). The main component in this carbon plate fabrication is activated carbon This activated carbon powder plays a role in absorbing high ions (Ahmed \& Tewari, 2018). Plate fabrication uses activated carbon synthesized from coconut shell powder. This material is very common in Indonesia. The carbon plates that have been made are arranged in parallel(Jain et al., 2018). Testing of capacitive desalination systems is carried out by evaluating the desalination ability of the system to variations in the flow rate of the salt solution.

\section{Research Methods}

The fabrication of carbon plates was carried out by mixing the polymer, activated carbon, and GA binder stages; furnace printing, and baking(K. K. Park et al., 2007). The plate fabrication stage begins with mixing the solution between 1 gram of PVA polymer and fifty $\mathrm{mL}$ of distilled water which is done by mixing using a stirrer device. After thirty minutes of stirring, twenty grams of activated carbon and half a gram of glutaric acid as a crosslinker agent are added to the polymer mixture and water and stirring for 480 min until the mixture becomes completely homogeneous (Rommerskirchen et al., 2015). The activated carbon mixture is then printed on an aluminum mold measuring $8 \mathrm{~cm}$ long, $6 \mathrm{~cm}$ wide, and $0.3 \mathrm{~cm}$ high. The plates that have become solid and dry enough are then baked in the furnace for one hour at a temperature of $120{ }^{\circ} \mathrm{C}$. The stages of making electrodes are shown in Figure 1 and Figure 2.

In the process of determining the electrochemical properties and behavior of a carbon electrode, a test process is carried out using a cyclic voltammetry method and the electrical impedance spectroscopy (K. K. Park et al., 2007). The carbon electrode plate is immersed in the specimen holder which has an area of 1 $\mathrm{cm} 2$. In the immersion process, an electrolyte solution of $0.5 \mathrm{M} \mathrm{KCl}$ was used at a measuring temperature of 25oC. Tests using a cyclic voltammetry tool were carried out at a potential of $-05 \mathrm{~V}$ to $0.5 \mathrm{~V}$ (vsAg / $\mathrm{AgCl}$ ). The speed used is a potential sweep of $5 \mathrm{mV} / \mathrm{s}$. The next test used Electrical Impedance Spectroscopy at a potential of $0.0 \mathrm{~V}$ with a frequency of $100 \mathrm{~Hz}$ to 20 $\mathrm{mHz}$ and a peak-to-peak sinusoidal signal of $25 \mathrm{mV}$. The test uses cyclic voltammetry and the EIS test, which is used to calculate the capacitance and specific resistance values of the carbon electrode plate

The ability of the carbon plate desalination system in the process of removing salt content in the solution is tested by arranging five pairs of electrodes in parallel. the solution being tested flows between the surfaces of a pair of carbon 


\section{Pramartaningthyas}

plates. The desalination system scheme can be shown in Figure 3.
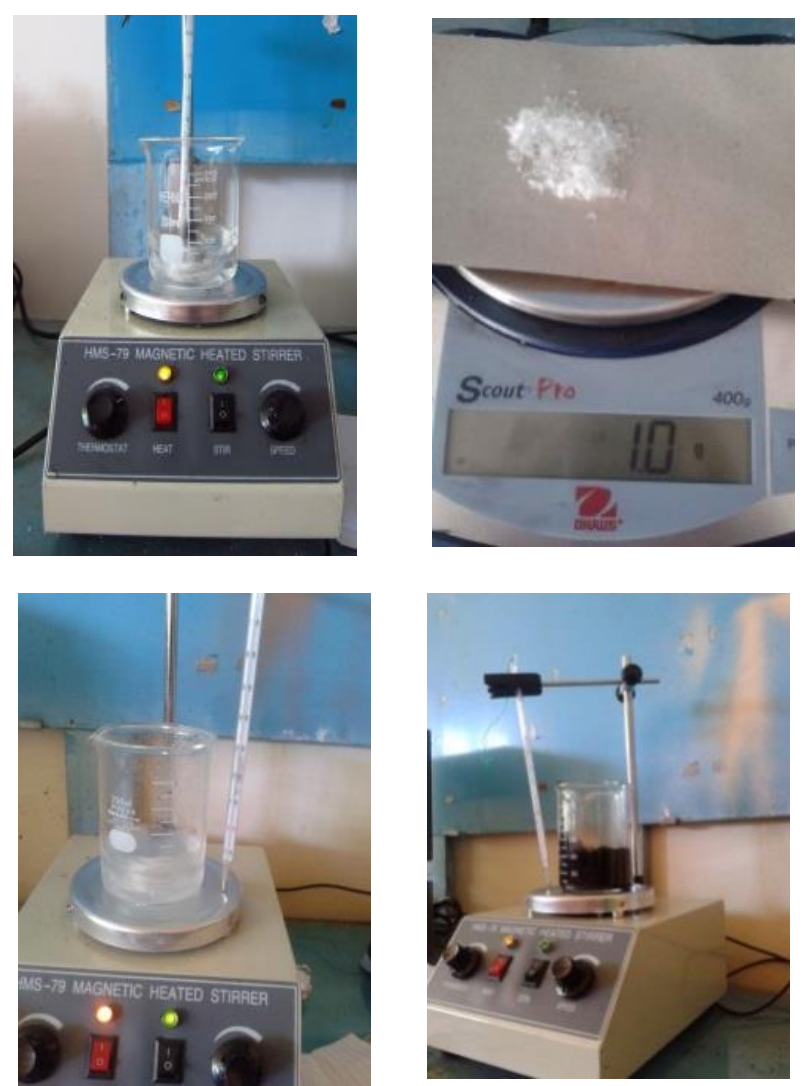

Figure 1. Mixing Activated carbon, binder, and PVA
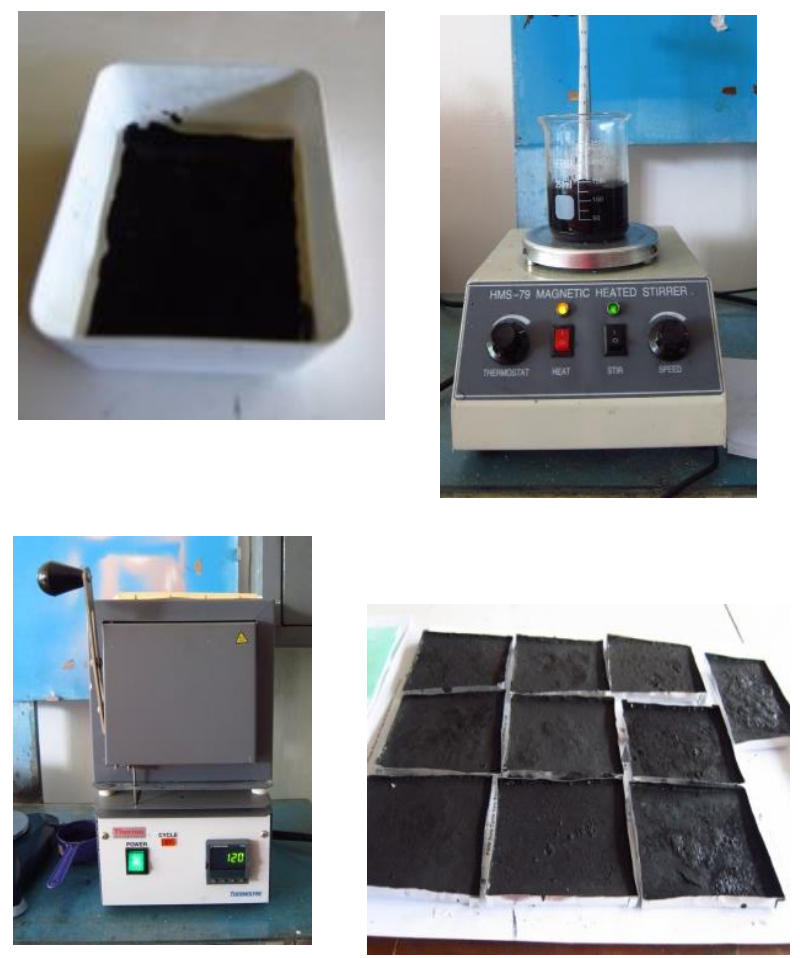

Figure 2. Forming and furnishing carbon plates

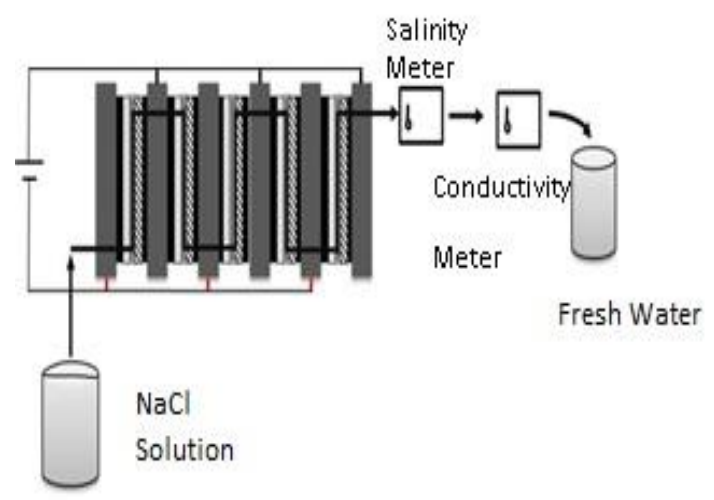

Figure 3. Desalination system

The desalination system consists of a tank for 0.5 $\mathrm{M} \mathrm{NaCl}$ salt solution, a manual valve to control the flow rate, a CDI cell consisting of 5 cells, and a tank to accommodate the desalination results as shown in Figure 4. The desalination system that has been built is tested with alteration of the flow rate of the solution which will be tested, namely at a rate of $25 \mathrm{cc} / \mathrm{min}, 20$ $\mathrm{cc} / \mathrm{min}, 15 \mathrm{cc} / \mathrm{min}, 10 \mathrm{cc} / \mathrm{min}$, and $5 \mathrm{cc} / \mathrm{min}$.

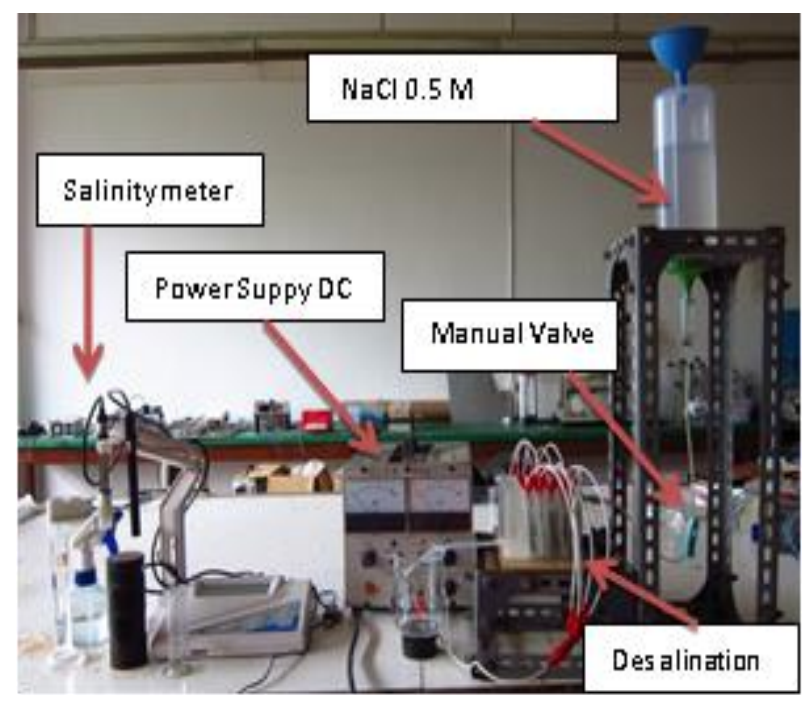

Figure. 4 Desalination System Cells

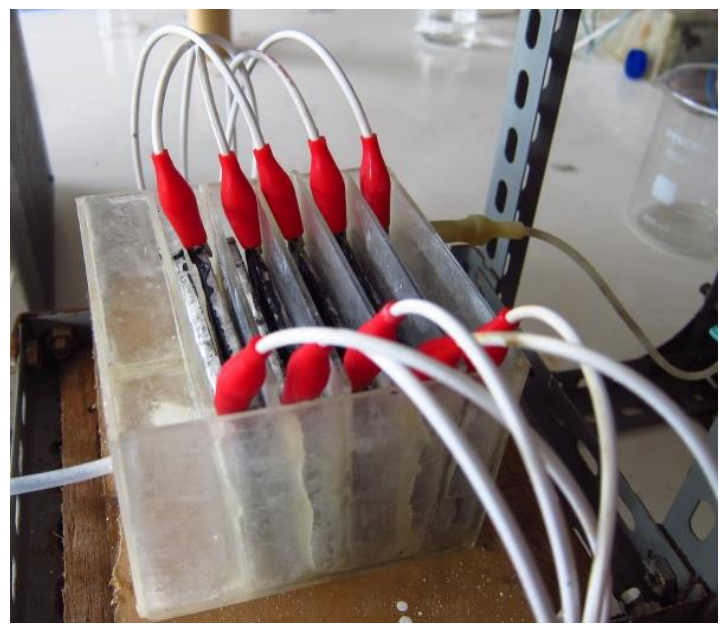

Figure. 5 Desalination System 


\section{Result and Discussion}

\section{Testing of Carbon Electrode Morphology}

The shape of the carbon plate that is fabricated with polyvinyl alcohol binder is strongly influenced by the amount of binder, namely glutaric acid which is used in the manufacture of carbon plates. To increase the number of salt solution ions that can be absorbed by the carbon plate, the plate plane structure (Figure 2) must have a high number of pores in a concrete form and micrometer width, and evenly across the surface of the plate (Zhao et al., 2013).

Figure 2 shows the surface of the porous plate that is formed quite evenly distributed on the electrode plate with a size of 2 micrometers. This is due to the cross-link between polyvinyl alcohol and glutaric acid. This link connects the binder, activated carbon, and glutaric acid to form a dense solid. while the structure of the plate surface will form a network with the addition of glutaric acid (Guo et al., 2020).

As a testing machine in the process of observing the morphology of certain material surfaces, the Scanning Electron Microscope (SEM) can describe more detailed forms (both micro and macro structures of material). The surface structure observed using SEM is the surface structure of the carbon plate which is very influenced by its forming structures, namely activated carbon, binder, and PVA (B. H. Park et al., 2011). As in the research conducted by (B. H. Park et al., 2011), the surface structure of the carbon electrode plate will be in the form of discrete particles or small rods. This carbon electrode plate, which was made at a temperature of $120^{\circ} \mathrm{C}$, formed many pores on the carbon surface. These pores play a very important role in the process of absorption of salt ions in the system(Nulik \& Endarko, 2017). The mixing of the binder and PVA will form a solid which is not soluble in water and is compact. the bond between the binder and the PVA is perfectly formed on all parts of the electrode while for a temperature of $120^{\circ} \mathrm{C}$ the crosslinking bond is spread more evenly and is more porous (Choi \& Choi, 2010).

Testing of Cyclic Voltammetry and Electrical Impedance Spectroscopy.

Cyclic voltammetry tests were carried out for the importance of electrochemical analysis on carbon plates (Mutha et al., 2018). Figure 3 below imaged the voltammetric test chart of the carbon electrode plate.
Analysis of electrochemical processes on the surface of the electrode plate can use a cyclic voltammetric test. In this testing process, an electrochemical system consisting of two carbon electrode plates and an electrolyte solution will be applied with an electric potential of $0.5 \mathrm{~V}$ then an electric potential is applied with the opposite pole, namely $-0.5 \mathrm{~V}$ using a sweep rate of $5 \mathrm{mV} / \mathrm{min}$. The electric potential applied to the carbon electrode causes the electrolyte ions to be pushed as a result of the application of electrical energy to the surface of the carbon electrode plate (Welgemoed \& Schutte, 2005). Electrolyte ions are then absorbed through the pores on the entire area of the plate. When an electric potential is applied with the opposite pole, this movement will be detected as an electric current on the voltammogram imaging (Demirer et al., 2013). In the testing process of this research, the moving current at a value of $0.00575 \mathrm{~A}$ indicates the absorption of ions in the carbon plate and becomes a zero value Amperes indicating the ions are released again towards electrolyte solutions (Rommerskirchen et al., 2015).

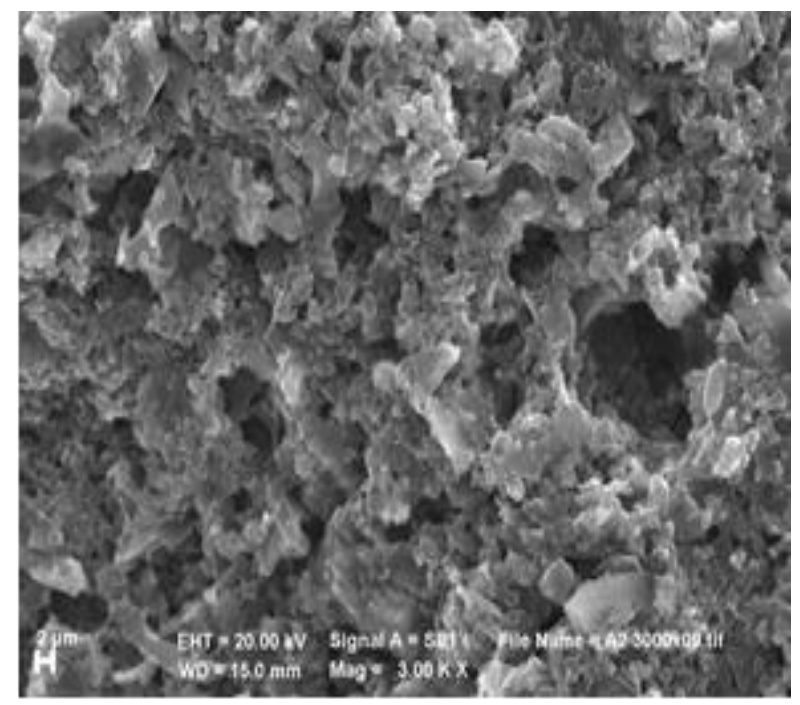

Figure 2. Carbon plate morphology by SEM testing

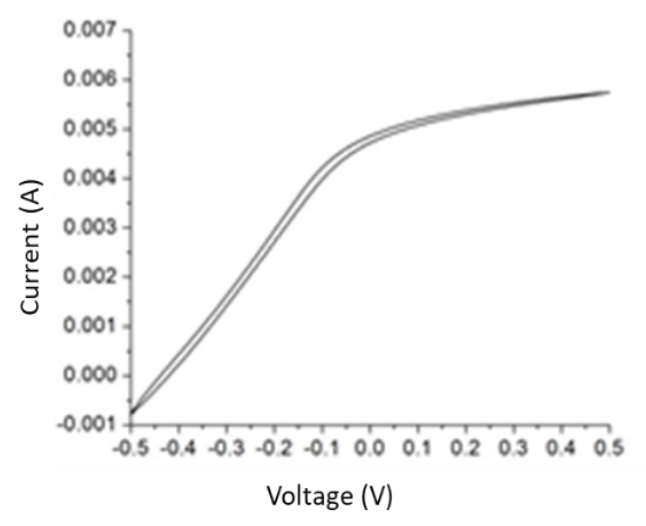

Figure. 3 Cyclic voltammetry test results 


\section{Pramartaningthyas}

\section{Testing Desalination System Signal Response}

Oscilloscope imaging is used for testing the signal response in the desalination system to the absorption and desorption processes that occur in the desalination system. The signal response describes the process of charge absorption and discharges in the electrode plate plane (Zhang et al., 2019). The input voltage of one and a half volts, which is the value of the electric potential used in the system in the desalination process, is applied to the electrode with form a signal box and run periodically generated from the signal generator function. Furthermore, the output signal of the capacitive deionization system can be analyzed according to Figure 4 . In this graph, it can be seen that there is a process of absorption and release of ions under the input signal pattern with the signal caps applied to the system, and the electrodes that have been made are capacitive.

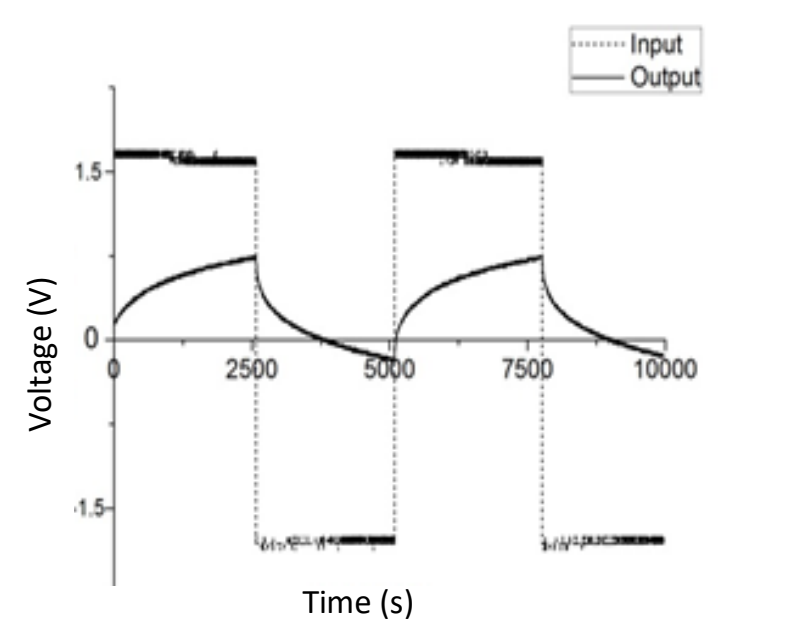

Figure 4. discharge pattern in a desalination system with a Yokogawa DL 1640 digital oscilloscope

\section{Flow velocity variations}

Several aspects have an impact on the performance of the capacitive desalination system in the process of absorbing salt ions (Hawks et al., 2018). The movement of salt ions towards the surface of the electrode determines the number of salt ions absorbed into the surface of the carbon plate (Remillard et al., 2018). The faster the rate of electrolyte solution applied to the desalination system, the salt ions will tend to be pushed by the flow current than those affected by the electric fields on the two carbon plates (Remillard et al., 2018). Conversely, the slower flow rate of the electrolyte solution is also less effective for the performance of the desalination system because it will produce freshwater products with low volume and long operational duration (Mutha et al., 2018)(Carmona-Orbezo \& Dryfe, 2021). Figure 5 shows the data on the reduction of salt content in the desalination process where the data is taken from the reduction in the conductivity of the solution every 5 minutes in 60 minutes. Based on the data from the test results of reducing the conductivity of the solution, it is found that the best performance in the desalination process occurs in a flow of $10 \mathrm{~mL} / \mathrm{min}$.

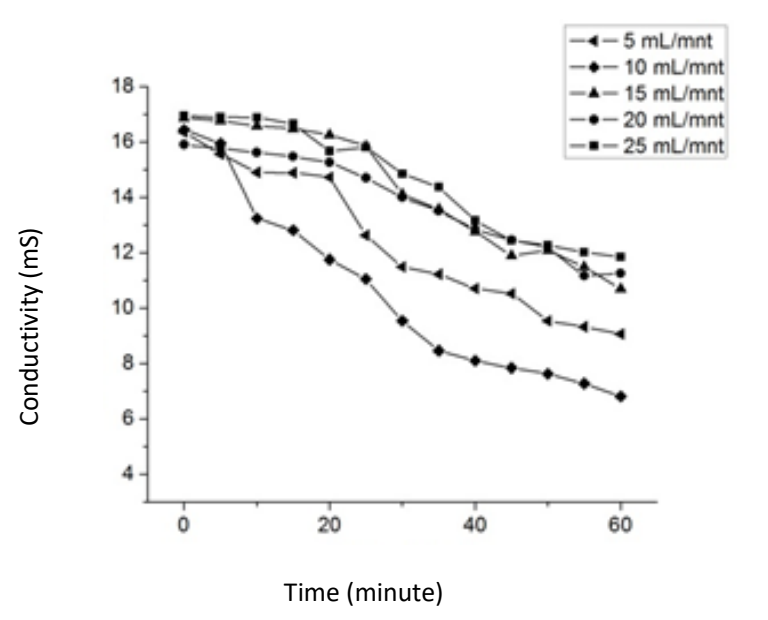

Figure 5. Desalination results based on electrolyte flow rate alteration

The performance of the conductivity reduction in the system that has been made and the flow rate variation is carried out, the percentage data for the reduction in salinity of each is obtained as follows: a reduction in conductivity of $44.62 \%$ for a flow rate of $5 \mathrm{~mL} / \mathrm{min}, 58.58 \%$ for a flow rate of $10 \mathrm{~mL} / \mathrm{min}, 36.57 \%$ for a flow rate of 15 $\mathrm{mL} / \mathrm{min}, 32.88 \%$ for a flow rate of $20 \mathrm{~mL} / \mathrm{min}$ and at a flow rate of $25 \mathrm{~mL} / \mathrm{min}$ obtained a reduction in salinity of $30.09 \%$. Based on the data above, it can be seen that the higher the flow rate is applied to the system, the smaller the reduction in salt content in the system. This is caused by the accelerating flow of the current which makes the ions unable to be attracted by the electric field at the two carbon electrodes.

The material on the carbon electrode must have a minimum specific surface area or area per unit weight of approximately $1000 \mathrm{~m} 2 /$ gr to absorb salt ions in the solution. In this specific area of $1000 \mathrm{~m} 2 / \mathrm{gr}$, the desalination process in the carbon electrode system consists of two subs. The process is desalination where ions are absorbed in the electrode and the second is regeneration where ions are desorbed from the electrodes. 


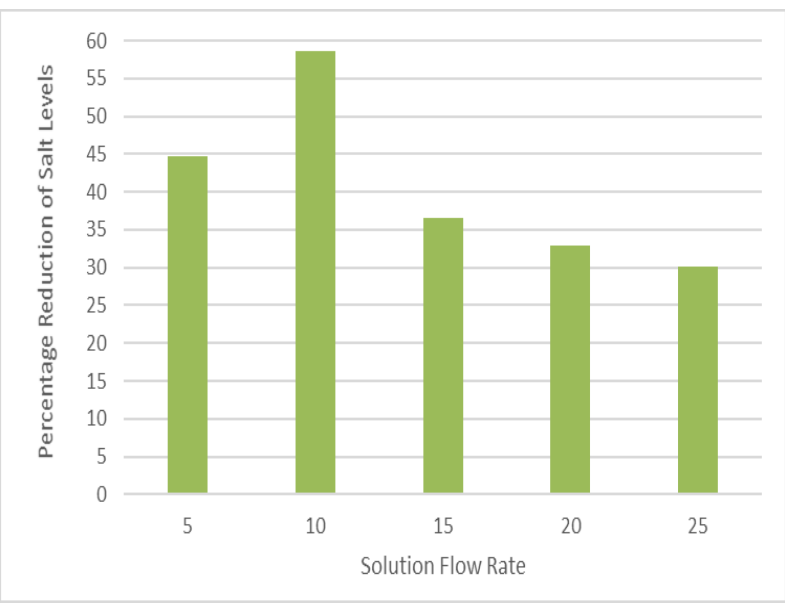

Figure 6. Reduction Percentage of Salt Content to solution flow rate

During the salt absorption process, the electric potential energy supplied by the power supply initiates an electric field between the two carbon plates to separate the salt ions based on their polarity. When the solution flow has a high speed, the dissolved ions enter the output stream so that the ions are released from the electric force bonds that occur between the two carbon plates. Meanwhile, with the right speed, the salt ions will be attracted by the electric field generated by the source voltage on the carbon plate. This results in an output stream that has a low ion concentration. When desalination is carried out to the limit of the electrode capacity, no ions can be collected, so no change will occur in the concentration of the inlet and outflow until the system is regenerated. Regeneration in the system is done by reversing the voltage on the electrodes so that the ions are released into the flow.

\section{Conclusion}

The production of this capacitive deionization system uses the working principle of a capacitor, namely by using a carbon plate that can absorb salt ions in an electrolyte solution with the help of the effect of an electric field on the carbon plate. The carbon electrode is made of activated carbon, PVA, and glutaric acid. The system operates effectively with a reduced salt content of $58.58 \%$ for systems with a flow rate of $10 \mathrm{~mL} / \mathrm{min}$. The experimental results show that the greater the flow rate applied to the system, the smaller the decrease in salt content in the system

\section{References}

Ahmed, M. A., \& Tewari, S. (2018). Capacitive deionization: Processes, materials, and state of the technology. Journal of
Electroanalytical Chemistry, 813, 178-192. https://doi.org/10.1016/J.JELECHEM.2018.0 2.024

Carmona-Orbezo, A., \& Dryfe, R. A. W. (2021). Understanding the performance of flowelectrodes for capacitive deionization through hydrodynamic voltammetry. Chemical Engineering Journal, 406, 126826. https://doi.org/https://doi.org/10.1016/j.cej.20 20.126826

Choi, J. Y., \& Choi, J. H. (2010). A carbon electrode fabricated using a poly(vinylidene fluoride) binder controlled the Faradaic reaction of carbon powder. Journal of Industrial and Engineering Chemistry. https://doi.org/10.1016/j.jiec.2009.08.005

Demirer, O. N., Clifton, R. L., Perez, C. A. R., Naylor, R., \& Hidrovo, C. (2013). Characterization of Ion Transport and Sorption in a Carbon-Based Porous Electrode for Desalination Purposes. Journal of Fluids Engineering, 135(4), 041201. https://doi.org/10.1115/1.4023294

El-Deen, A. G., Barakat, N. A. M., Khalil, K. A., \& Kim, H. Y. (2014). Hollow carbon nanofibers as an effective electrode for brackish water desalination using the capacitive deionization process. New Journal of Chemistry. https://doi.org/10.1039/c3nj00576c

Fritz, P. A., Boom, R. M., \& Schroen, K. (2019). Polyelectrolyte-activated carbon composite electrodes for inverted membrane capacitive deionization (iMCDI). Separation and Purification Technology. https://doi.org/10.1016/j.seppur.2019.03.053

Guo, L., Ding, M., Yan, D., Pam, M. E., Vafakhah, S., Gu, C., Zhang, W., Valdivia y Alvarado, P., Shi, Y., \& Yang, H. Y. (2020). Highspeed capacitive deionization system with flow-through electrodes. Desalination, 496, 114750. https://doi.org/https://doi.org/10.1016/j.desal. 2020.114750

Hawks, S. A., Knipe, J. M., Campbell, P. G., Loeb, C. K., Hubert, M. A., Santiago, J. G., \& Stadermann, M. (2018). Quantifying the flow efficiency in constant-current capacitive deionization. Water Research, 129, 327-336. https://doi.org/10.1016/J.WATRES.2017.11. 025 


\section{Pramartaningthyas}

Jain, A., Kim, J., Owoseni, O. M., Weathers, C., Caña, D., Zuo, K., Walker, W. S., Li, Q., \& Verduzco, R. (2018). Aqueous-Processed, High-Capacity Electrodes for Membrane Capacitive Deionization. Environmental Science and Technology. https://doi.org/10.1021/acs.est.7b05874

Mutha, H. K., Cho, H. J., Hashempour, M., Wardle, B. L., Thompson, C. V., \& Wang, E. N. (2018). Salt rejection in flow-between capacitive deionization devices. Desalination, 437 , $154-163$. https://doi.org/10.1016/J.DESAL.2018.03.00 8

Nulik, B. W., \& Endarko. (2017). Performance analysis of carbon electrode synthesized with poly (vinyl alcohol) and citric acid as crosslinking agents for desalination of $\mathrm{NaCl}$ solution in capacitive deionization. AIP Conference Proceedings. https://doi.org/10.1063/1.4968360

Oren, Y. (2008). Capacitive deionization (CDI) for desalination and water treatment - past, present, and future (a review). Desalination, 228(1-3), 10-29. https://doi.org/10.1016/J.DESAL.2007.08.00 5

Park, B. H., Kim, Y. J., Park, J. S., \& Choi, J. (2011). Capacitive deionization using a carbon electrode prepared with water-soluble poly(vinyl alcohol) binder. Journal of Industrial and Engineering Chemistry. https://doi.org/10.1016/j.jiec.2011.05.015

Park, K. K., Lee, J. B., Park, P. Y., Yoon, S. W., Moon, J. S., Eum, H. M., \& Lee, C. W. (2007). Development of a carbon sheet electrode for electrosorption desalination. Desalination.

https://doi.org/10.1016/j.desal.2006.04.051

Remillard, E. M., Shocron, A. N., Rahill, J., Suss, M. E., \& Vecitis, C. D. (2018). A direct comparison of flow-by and flow-through capacitive deionization. Desalination, 444, 169-177.

https://doi.org/10.1016/J.DESAL.2018.01.01 8

Rommerskirchen, A., Gendel, Y., \& Wessling, M. (2015). Single module flow-electrode capacitive deionization for continuous water desalination. Electrochemistry Communications, 60, 34-37. https://doi.org/10.1016/J.ELECOM.2015.07.
018

Welgemoed, T. J., \& Schutte, C. F. (2005). Capacitive Deionization Technology ${ }^{\mathrm{TM}}$ : An alternative desalination solution. Desalination, 183(1-3), 327-340. https://doi.org/10.1016/J.DESAL.2005.02.05 4

Wu, T., Wang, G., Zhan, F., Dong, Q., Ren, Q., Wang, J., \& Qiu, J. (2016). Surface-treated carbon electrodes with modified potential of zero charge for capacitive deionization. Water Research. https://doi.org/10.1016/j.watres.2016.02.004

Zhang, C., He, D., Ma, J., Tang, W., \& Waite, T. D. (2019). Comparison of faradaic reactions in flow-through and flow-by capacitive deionization (CDI) systems. Electrochimica Acta, 299, 727-735. https://doi.org/10.1016/J.ELECTACTA.2019. 01.058

Zhao, R., Satpradit, O., Rijnaarts, H. H. M., Biesheuvel, P. M., \& van der Wal, A. (2013). Optimization of salt adsorption rate in membrane capacitive deionization. Water Research, 47(5), 1941-1952. https://doi.org/10.1016/J.WATRES.2013.01. 025 